\title{
When should a territory resident attack?
}

\author{
PAUL V. SWITZER*, JUDY A. STAMPS $†$ \& MARC MANGEL $\ddagger$ \\ ${ }^{*}$ Department of Biological Sciences, Eastern Illinois University \\ $\dagger$ Section of Evolution and Ecology, University of California, Davis \\ \$Department of Environmental Studies, University of California, Santa Cruz \\ (Received 10 August 2000; initial acceptance 2 October 2000; \\ final acceptance 15 March 2001; MS. number: A8855)
}

\begin{abstract}
Models of territorial defence tend to omit two characteristics of many territorial systems: repeated intrusions by the same individual and the learning processes of residents and intruders. Here we present state-dependent, dynamic models of feeding territories, designed to investigate temporal patterns of resident aggression towards intruders that are capable of spatial learning. We compare two types of models: (1) a nomadic intruder model, in which intruders never visit the same territory twice, and (2) a single, repeat intruder model, in which an intruder may repeatedly intrude into a given territory but is less likely to do so after being attacked. These two models produce qualitatively and quantitatively different patterns of aggression by residents. For instance, residents with intruders that may repeatedly intrude have high initial attack rates, regardless of initial probability of intrusion, but their attack rates decline over time. In contrast, residents in the nomadic intruder model do not attack intruders if intrusion rates are moderately high, and their attack rates are constant and high for most of the period of territory tenure. In addition, residents of both nomadic and repeat intruder scenarios stopped attacking intruders for a short period before voluntarily abandoning their feeding territories. The results of our models suggest that repeated intrusions and learning processes have a dramatic effect on territorial defence.
\end{abstract}

( 2001 The Association for the Study of Animal Behaviour

For many years, models have played an important role in advancing our understanding of the role of aggression in territorial species. However, a dichotomy has arisen between models investigating territories and models investigating aggressive behaviour. Most territory models focus on an individual versus the rest of the population, and consider such questions as when space should be defended, how much space should be defended, or what shape a territory should be (e.g. Ebersole 1980; Hixon 1980; Schoener 1983; Poethke \& Kaiser 1987; Provencher \& Vickery 1988; Eason 1992). Generally, these territory models are static, and compare the costs and benefits of behaviours at a particular point in time (e.g. Davies 1978; Kodric-Brown \& Brown 1978; Myers et al. 1981; Schoener 1983; Carpenter 1987; Grant 1993; but see Dill 1978). In contrast, models of aggressive interactions typically focus on interactions between particular pairs of individuals and often use game theory; these models predict

Correspondence: P. V. Switzer, Department of Biological Sciences, Eastern Illinois University, 600 Lincoln Avenue, Charleston, IL 61920, U.S.A. (email: cfpvs@eiu.edu). J. A. Stamps is at the Section of Evolution and Ecology, University of California, Davis, CA 95616, U.S.A. M. Mangel is at the Division of Environmental Studies, University of California, Santa Cruz, CA 95064, U.S.A.

0003-3472/01/100749+11 \$35.00/0 who will win the contest, or the pattern of behaviours within a contest (e.g. Parker 1974; van Rhijn \& Vodegel 1980; Maynard Smith 1982; Enquist \& Leimar 1983; Grafen 1987; Nuyts 1994; Mesterton-Gibbons et al. 1996). Compared to the more spatially oriented territory models, models of animal contests tend to be more dynamic, and often investigate sequences of behaviours between individuals (e.g. Enquist \& Leimar 1983).

Many lines of evidence suggest that modelling territorial behaviour as a long-term, dynamic set of interactions between particular individuals would be useful. For example, territories are often defended for an extended period, suggesting that individuals may profit from a long-term view of their territorial occupation, rather than just a static snap-shot (e.g. Davies \& Houston 1983; Stamps \& Tollestrup 1984; Gordon 1995). Furthermore, in any territorial species whose members establish stable home ranges in or near territorial neighbourhoods, individuals can repeatedly intrude into particular territories: examples include species in which neighbours regularly intrude into one another's territories (Temeles 1994; Gordon \& Kulig 1996), or in which 'floaters' living in or near territorial neighbourhoods repeatedly intrude into nearby territories (e.g. Smith 1978; Arcese 1987; Stamps \& Eason 1989; Rohner 1997). 
Invasions of a territory by an intruder often elicit aggressive responses from the resident; this aggression is assumed to induce the intruder to leave the territory (reviews in Waser \& Wiley 1979; Huntingford \& Turner 1987; Archer 1988; Stamps 1994). However, in animals capable of spatial learning, aggressive interactions between residents and intruders may have the additional consequence of reducing the chances that the intruder will return to that territory at a later time (Stamps \& Krishnan 1999). That intruders may be capable of spatial learning seems reasonable, given the fact that territory residents in the same species are capable of learning the location of their territories and their boundaries (Waser \& Wiley 1979; Patterson 1980; Stamps \& Krishnan 1999). Most existing models of territory defence, however, do not include learning processes when investigating aggressive behaviour.

The notion that residents use punishment to 'train' intruders to avoid their territories is consistent with suggestions from comparative psychologists that 'from an evolutionary viewpoint, conspecific aggression and conspecific "punishment" are virtually the same thing' (Blanchard \& Blanchard 1986, page 153), a point recently echoed by behavioural ecologists (e.g. Clutton-Brock \& Parker 1995). If this perspective is valid, then the extensive psychological literature on the effects of rewards and punishment on space use may yield powerful insights into the proximate processes responsible for generating territorial spacing patterns. In fact, a recent learningbased model of territory establishment is capable of generating many phenomena similar to those observed in territorial animals, including the formation of stable territories within larger patches of uniform quality habitat, increased home range exclusivity when settlers are aggressive to one another, and a prior residency advantage whenever previous residents and newcomers compete for the same space (Stamps \& Krishnan 1999). Thus, Stamps \& Krishnan (1999) illustrated the value of considering learning processes when examining territorial behaviour.

In summary, two potentially key characteristics of many territorial systems (repeated interactions with the same individual and learning processes) are missing from models investigating aggressive behaviour between territorial residents and intruders. In this paper, we begin to investigate the effects of these processes on territorial behaviour. We assume that intruders are capable of spatial learning and that attacks by residents discourage intruders from returning to the territory at a later time. We incorporate these assumptions into models in which residents defend feeding territories, and in which the fitness of residents is affected by the amount of energy accrued from the territory, minus the energetic costs of defending the territory against intruders. Based on the assumption that territory residents occupy territories over a finite period, and that their energetic state at the end of this period affects their fitness, we construct a dynamic model to determine optimal patterns of aggressive behaviour for territory residents, as a function of responses of intruders to previous attacks on those territories. In particular, we compare resident behaviour when faced with nomadic intruders, which do not return to the territory if evicted, with situations in which residents are faced with a single intruder that may return after being evicted.

Thus, our model uses a relatively simple approach to study spatial and learning aspects of territorial behaviour (we explain and justify the details of the model more fully below). Our treatment of 'space' is limited to one resident's territory; however, the surrounding habitat may be considered meaningful in how it affects the intruders' behaviour (e.g. how persistent they are in repeatedly intruding into that resident's space). Learning, in our model, occurs only in the intruder and is represented by a decrease in the probability of intruding as a consequence of previous attacks (see below; Stamps \& Krishnan 1999). This treatment of learning is consistent with definitions that describe learning as a change in behaviour that results from the effects of experience on cognitive state, as opposed to a change in behaviour that results from other factors, including development, motor fatigue or sensory adaptation (e.g. Hinde 1970; Shettleworth 1998). This definition differs from a Bayesian approach, which treats learning as a process that reduces uncertainty (Hilborn \& Mangel 1997; Clark \& Mangel 2000). The current study differs in two important ways from Stamps \& Krishnan (1999), by focusing on interactions between territory residents and intruders after territories have been established, and by using a state-dependent, dynamic model to determine the optimal patterns of aggressive behaviour for territory residents in situations when aggression directed at intruders discourages them from visiting the territory in the future.

\section{MODEL FORMULATION AND METHODS}

Although we are modelling a single territory, we envision that residents establish feeding territories within large patches of habitat (neighbourhoods) that are also inhabited by nonterritorial individuals (intruders). Intruders are free to move among different areas in the patch, so that if they are expelled from a territory they have the option of visiting other defended or nondefended areas within the same neighbourhood. When intruders enter territories, they take food but do not challenge residents for ownership, and residents do not lose ownership to intruders (cf. Davies \& Houston 1981; Tricas 1989; Carpenter et al. 1993b; Temeles 1994). Residents inhabit their territories for a finite period of time, and they can accurately predict the duration of residency and the time when they will abandon their territories. In reality, cues such as photoperiod, temperature, feeding rate and growth rate may allow territory owners to estimate territory tenure (Carpenter et al. 1983; Stamps \& Tollestrup 1984). For the sake of simplicity, we assume that resource levels do not change over the territorial season, and that resource levels and quality are spatially homogeneous across the neighbourhood. In this situation, residents and intruders can accurately assess the resources available in any given territory on the basis of previous foraging experience in the same neighbourhood. 
Our model focuses on a knowledge asymmetry between residents and intruders that is probably common in territorial animals. By definition, 'residents' have lived in their territory for a finite period. If intruders enter territories sequentially, and if different intruders in a given neighbourhood display similar behaviour, then experience with previous intruders will allow residents to estimate how future intruders are likely to behave, as a consequence of being attacked by the resident. In other words, residents may use previous experience with intruders in the same territory, or in a different territory in the same neighbourhood, to assess the effects of their aggressive behaviour on intruders they are likely to encounter during the current season. In this situation, experienced residents will have the information required to behave appropriately when intruders enter their territory and therefore do not need to learn about the specific intruder on their territory.

In contrast, we assume that intruders entering a territory for the first time lack critical information about the social situation (e.g. whether the territory is occupied, whether they will be detected by the territory owner, and whether the owner will attack if they are detected). We assume that every territory is occupied and that a resident detects every intruder that enters its territory, but even in this simplified situation, our model predicts that residents vary with respect to whether or not they will attack the intruder (see below). Hence, we assume that most intruders need to learn about the social behaviour of the resident when entering a territory for the first time; as a result our model focuses on the effects of learning by intruders on the optimal defensive behaviour of residents.

A major aim of this study is to construct a residentintruder model with assumptions as similar as possible to those of classic models of feeding territory defence, in order to produce results directly comparable to those models. As a result, this model ignores other situations in which learning affects territorial behaviour. For instance, when newcomers establish home ranges and territories in previously empty patches of divisible habitat, 'residents' and 'intruders' do not yet exist, because all of the settlers are still in the process of learning about features of the habitat and one another (Stamps \& Krishnan 1999, 2001). In this situation, the assumption of knowledge asymmetries between opponents does not apply, and modelling approaches such as dynamic games (cf. Maynard Smith 1982; Bednekoff 1997; Barta \& Giraldeau 2000) would be more appropriate for predicting the optimal aggressive behaviour of different individuals during the settlement process. Hence, it is important to emphasize that the current model is designed for, and only applies to, cases in which there is a clear dichotomy between opponents, with respect to their ability to accurately predict the effects of their social and spatial behaviour on one another.

Our model diverges from classic models of territory defence (e.g. Davies 1978; Kodric-Brown \& Brown 1978; Myers et al. 1981; Schoener 1983) in two key respects. First, these models focus on the optimal behaviour of residents at a particular instant in time, whereas we use dynamic programming techniques to investigate optimal resident behaviour over the entire period of territory tenure. Second, these models assume that each intruder visit is independent of intruder experience on previous visits. This assumption is valid in situations in which intruders are 'nomadic', such that any given intruder is very unlikely to visit the same territory more than once. Thus, we have designed one 'nomadic' model, which allows us to compare the predictions of earlier static models with those of dynamic models, when learning by intruders is not an issue. In addition, we have designed a 'repeat intruder' model that assumes individual intruders are likely to visit the same territory more than once, where the probability of returning to a given territory depends on aggressive experience during previous visits. A mathematically equivalent interpretation of these two models would be as 'nonlearning intruder' (i.e. nomadic intruder) versus 'learning intruder' (i.e. repeat intruder) models. However, by focusing our interpretation on nomadic and repeat intruders, we are able to keep our assumptions about the learning capabilities of intruders the same (because all territorial animals are capable of some spatial learning; see Introduction) while only varying their propensity to intrude on the same territory.

\section{Effects of Aggression on Intruder Space Use}

We let $P(n)$ denote the probability that an intruder will appear, given that the territory holder has already expelled $n$ intruders (in the nomadic intruder case) or the same intruder $n$ times (in the repeat intruder case). In the nomadic intruder case, the probability that an intruder will be on the territory in any given time interval, $t$, is a constant so that

$$
P(n)=i_{\mathrm{O}}
$$

In contrast, in the repeat intruder case, we assume that attacks by the resident reduce the probability that the intruder will return to the territory. Many learning studies have indicated that relationships between experience and performance are best described as exponential functions (Anderson 1995); therefore, in the repeat intruder situation

$$
P(n)=i_{0} \exp \left(-\frac{n}{r}\right)
$$

where $r$ reflects intruder persistence in returning to the territory in the face of attack (Fig. 1), with larger values of $r$ representing more persistent intruders. Variation in intruder persistence in returning to areas in which it was previously attacked might occur as a result of differences in the resources available to an intruder outside of the territory. For instance, an intruder with access to many potential feeding sites in a neighbourhood might be less persistent in returning to a particular territory after being attacked there than an intruder living in a patch with only a few feeding sites. Here, we present results for a 


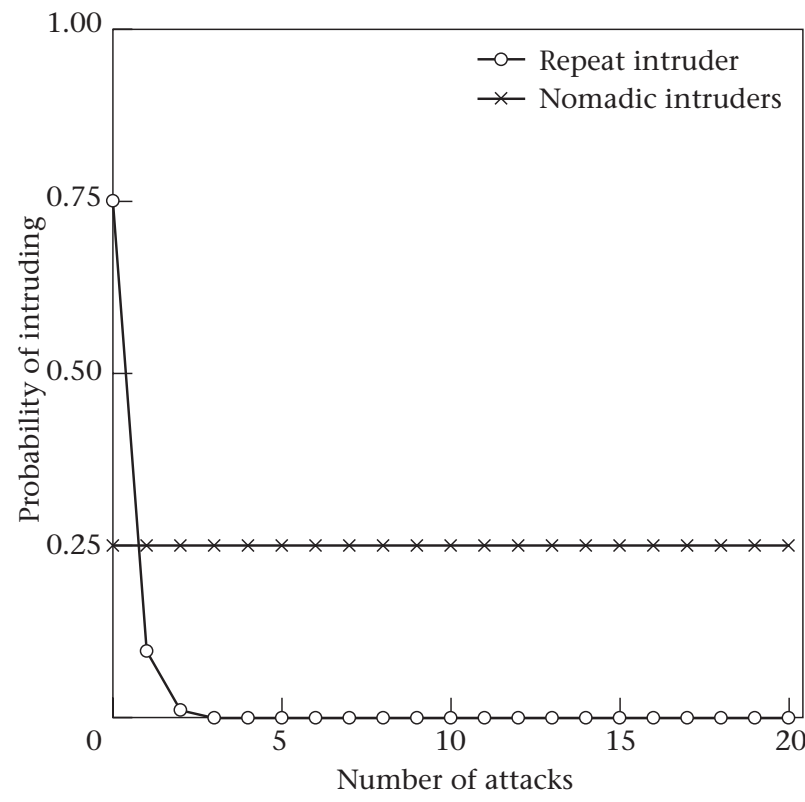

Figure 1. Functional forms for the response of intruders to resident attacks (see equations 1 and 2). The particular values correspond to those values used for illustration in the results: nomadic intruder $\left(i_{0}=0.25\right)$ and repeat intruder $\left(i_{0}=0.75, r=0.5\right)$.

relatively nonpersistent intruder $(r=0.5)$; results using larger values for $r$ were qualitatively similar.

\section{Monitoring the State of the Territory Resident}

Three variables represent the state of the resident individual.

\section{(1) Energy state of the resident: \\ $X(t)=$ energy state of the individual at the start of period $t$,}

which ranges between 0 and $x_{\max }$.

(2) Whether an intruder is present on the territory:

$$
S(t)=\left\{\begin{aligned}
= & 1 \text { if an intruder is present at } \\
& \text { the start of period } t \\
= & 0 \text { if an intruder is not present at } \\
& \text { the start of period } t
\end{aligned}\right.
$$

\section{(3) Expulsion history:}

$N(t)=$ number of expulsions

of intruders up to the start of period $t$

which ranges between 0 and $N_{\text {max }}$, determined so that another expulsion has little effect on the probability of intrusion (Fig. 1, Table 1).

We assume that fitness is related to the energetic state of the resident and that fitness is maximized when the energy accumulated at the end of the resident's tenure is maximized. We characterize fitness in terms of the three state variables, so that
Table 1. Parameter values for baseline runs

\begin{tabular}{|c|c|c|}
\hline Parameter & Description & $\begin{array}{l}\text { Baseline } \\
\text { value }\end{array}$ \\
\hline$y$ & Foraging value & 0.5 \\
\hline$d$ & $\begin{array}{l}\text { Divisor for sharing food with } \\
\text { intruder }\end{array}$ & 2 \\
\hline$\alpha_{d}$ & Fighting cost & 0.5 \\
\hline$\alpha_{f}$ & Foraging cost & 0.17 \\
\hline$i_{\mathrm{e}}$ & $\begin{array}{l}\text { Intruder impact on resident fitness } \\
\text { at the end of territory tenure }\end{array}$ & 1.0 \\
\hline \multirow[t]{2}{*}{$i_{0}$} & $\begin{array}{l}\text { Initial probability of intrusion } \\
\text { (repeat intruder) }\end{array}$ & 0.75 \\
\hline & $\begin{array}{l}\text { Initial probability of intrusion } \\
\text { (nomadic intruders) }\end{array}$ & 0.25 \\
\hline$N_{\max }$ & Maximum number of expulsions & 25 \\
\hline$r$ & Intruder persistence & 0.5 \\
\hline$T$ & Length of territory tenure & 16 \\
\hline$x_{\max }$ & Maximum energy reserves & 50 \\
\hline
\end{tabular}

See Model Formulation for more specific descriptions, associated equations and justification.

$$
\begin{gathered}
F(x, s, n, t)=\text { maximum expected value of fitness } \\
\text { at time } t \text { for an individual with } \\
\\
X(t)=x, S(t)=s \text {, and } N(t)=n,
\end{gathered}
$$

where fitness at the terminal time $T$ depends upon physiological state and whether or not an intruder is present

$$
F(x, s, n, T)=\frac{x}{x_{\max }} I(s)
$$

where $x / x_{\max }$ is the amount of energy the resident has relative to the maximum, and the function $I(s)$ devalues this payoff according to whether an intruder is present at time $T$,

$$
I(s)=\left\{\begin{array}{l}
=1 \text { if } s=0 \\
=i_{\mathrm{e}} \text { if } s=1
\end{array}\right.
$$

where $i_{\mathrm{e}}$ ranges between 0 (intruder eliminates resident's fitness) and 1 (intruder has no effect on the resident's fitness). Alternatives to this formulation could easily be incorporated.

When a resident forages, it receives an energetic gain $y$ if there is no intruder and a discounted gain $y / d$ if an intruder is present; the energetic cost of foraging is $\alpha_{\mathrm{f}}$. Because gut capacity and processing efficiency will limit the amount of energy gain an individual can experience in a short period (Schmidt-Nielson 1984), parameter values were chosen so that the increase in energy state in one period was less than $20 \%$ of its current value (see below). Thus, during time periods when there are no intruders on the territory, the resident forages alone, and its energy state $X(t)=x$ is incremented by

$$
g_{\mathrm{o}}(x)=y-\alpha_{\mathrm{f}}
$$


Thus, the fitness for a resident with $X(t)=x$ and $N(t)=n$ is

$$
\begin{gathered}
F(x, 0, n, t)=P(n) F\left(x+g_{\circ}(x), 1, n, t+1\right) \\
\quad+(1-P(n)) F\left(x+g_{\circ}(x), 0, n, t+1\right)
\end{gathered}
$$

where $P(n)$ is given by either equation (1) or equation (2). Nonintegral values of $x$ are calculated by linear interpolation (Clark \& Mangel 2000).

If an intruder is on the territory, the individual may either ignore the intruder and forage, or attack and expel the intruder and not forage. If it ignores the intruder, the energy increment is

$$
g_{\mathrm{f}}(x)=\frac{y}{d}-\alpha_{\mathrm{f}}
$$

Because the intruder was not expelled, the intruder remains on the territory at the start of the next time period. Hence, the expected fitness value for foraging with an intruder on the territory, at energy state $x$ and number of expulsions $n$ is (only one intruder is allowed)

$$
V_{\mathrm{f}}=F\left(x+g_{\mathrm{f}}(x), 1, n, t+1\right)
$$

If the resident attacks and expels the intruder, its energy state is decremented by the energetic cost $\alpha_{\mathrm{d}}$. We assume that the resident is always successful in defending its territory (i.e. expelling the intruder), so the number of expulsions is incremented by 1 . The fitness value of defending a territory is thus

$$
\begin{gathered}
V_{\mathrm{d}}=P(n) F\left(x-\alpha_{\mathrm{d}}, 1, n+1, t+1\right) \\
+(1-P(n)) F\left(x-\alpha_{\mathrm{d}}, 0, n+1, t+1\right)
\end{gathered}
$$

Maximum fitness for an individual currently sharing a territory is then determined by comparing the two options

$$
F(x, 1, n, t)=\max \left[V_{\mathrm{t}}, V_{\mathrm{d}}\right]
$$

\section{Analyses}

Equation (14) is solved by backwards iteration (Clark \& Mangel 2000). The results yield the optimal decisions for an individual at a particular time $t$, with any energy state $x$, intruder presence $s$, and number of expulsions $n$. Thus, the final product is a temporal sequence of behaviours (forage with no intruder present, forage and ignore the intruder, or expel the intruder and do not forage) conditioned on the state of an individual. During a resident's territory tenure, its state will change as a result of its behaviours; the resident's resultant state will then dictate the best behaviour at that time, which will determine its new state, and so on until the end of its tenure. Therefore, in order to understand how these variables affect the pattern of territorial defence for the duration of a resident's tenure, we constructed a forward simulation model that used the set of optimal behaviours. The forward model started with a resident at time period 1, with a given set of parameter values, and used a random number generator to determine what probabilistic events (e.g. intruding) occurred. Given the specific event, the resident behaved optimally according to the previously determined, optimal behaviour for that time period and state of the resident.

Our primary aim was to investigate how an intruder's response to resident aggression affected the pattern of a resident's aggression during its territory tenure. Consequently, we conducted runs of the model while varying $r$ (range 0.25 (rapid learning)-3.0 (slow learning)) and $i_{0}(0.1-1.0)$. To determine baseline parameter values, we conducted sensitivity analyses on the following parameters (with the tested range in parentheses): intruder effect at $T, i_{\mathrm{e}}(0-1.0)$; territory tenure, $T(11-51)$; maximum energy level, $x_{\max }(25$ and 50$)$; value of foraging, $y$ (0.3-1.0); and starting energy reserves (10-40). The foraging cost $\left(\alpha_{\mathrm{f}}\right)$, fighting cost $\left(\alpha_{\mathrm{d}}\right)$ and food share $(d)$ were all closely related and thus we explored different combinations of these values. Qualitatively, the model was robust to changes in the values of these parameters. We therefore chose a set of baseline values to be within the range of values that provided meaningful behaviour (Table 1).

In most of our runs, all residents started with the same energy reserves; however, in nature, residents may vary in their starting energy reserves. To determine how this variation in starting energy might affect territorial defence, for some runs we randomly assigned an energy state between 0 and $x_{\max }$ to each individual from a uniform distribution of possible energy states. Not surprisingly, the variation in starting reserves generated more variation in behaviour among individuals (e.g. exactly how many individuals were fighting at a given time). Qualitatively, however, the results were very similar to those runs with equal starting energy reserves. Because the patterns were similar and because we wanted to keep the interpretations of our results as simple as possible, we only present the results of runs where all individuals started with equal energy.

Results consist of averages of 10000 territories. To summarize our results, we calculated the percentage of these territories that: (1) had intruders on them; (2) had fighting on them; and (3) had intruders and fighting on them. For clarity, we present the results of one repeat intruder case $(r=0.5)$ and one nomadic intruder case $\left(i_{0}=0.25\right)$. The functional forms of these values are given in Fig. 1.

\section{RESULTS}

\section{Responses of Residents and Intruders Early in the Tenure Period}

The response of residents to intruders that enter the territory in period 1 depends on two factors: the type of intruder and the initial probability of intrusion $\left(i_{0}\right)$. For the nomadic intruder model, residents always attack intruders in period 1 if $i_{0}$ is lower than a threshold value (Fig. 2). No such threshold exists for the repeat intruder model; intruders are always attacked in the initial period (Fig. 2). 


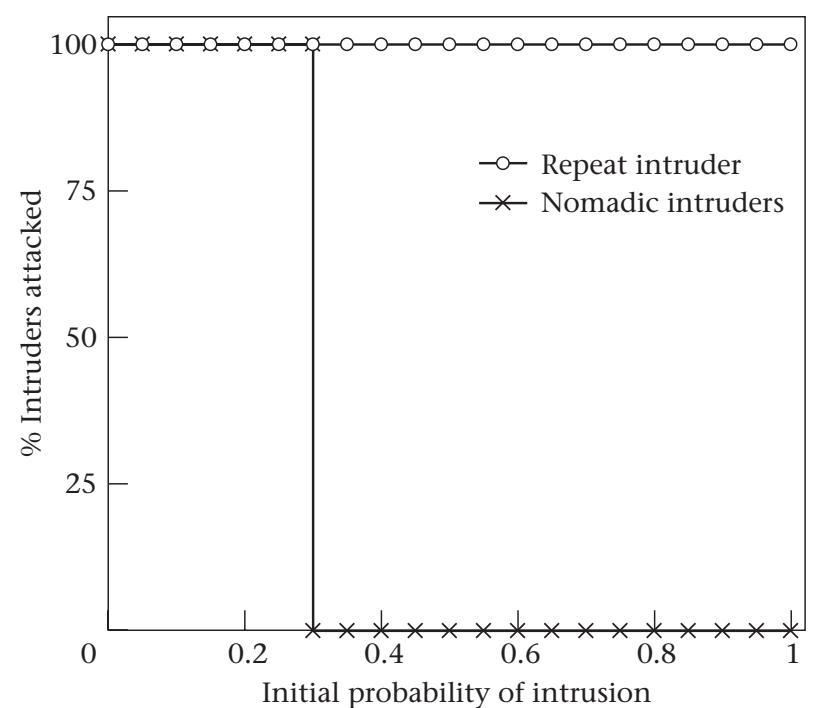

Figure 2. Percentage of residents attacking intruders in the first period versus the initial probability of intrusion $\left(i_{0}\right)$. Percentage is calculated from those territories that had an intruder in the first period. See Fig. 1 for the functional forms of intrusion probability for repeat and nomadic intruders and Table 1 for parameter values.

The threshold for attack differs between repeat and nomadic intruder cases due to the different consequences of attack on future intrusions. When a resident is interacting with a single, repeat intruder, initial attacks on this intruder reduce the chance that the intruder will intrude in the future. Thus, even if $i_{0}$ is very high, the subsequent probability of intrusion declines later in the tenure period. In contrast, in the nomadic intruder model, $i_{\mathrm{O}}$ is unaffected by the resident's previous aggressive behaviour and therefore remains constant throughout the resident's tenure. Therefore, the future expected probability of an intrusion is higher for the residents with nomadic intruders than those with repeat intruders.

In both the nomadic and repeat intruder models, if residents are not aggressive to intruders during period 1 , they are never aggressive to any intruders that enter later during their tenure. This is because residents attacking at the beginning of their tenure have the longest time available for recouping their defence cost; thus, if it is not beneficial for the resident to attack in period 1 , it will be even less beneficial to attack later in the tenure. Furthermore, if the resident attacked intruders in period 1 , it also attacked intruders throughout the first portion of its territory tenure (Fig. 3). The length of the defence period varies with the initial probability of intrusion, with higher values leading to shorter periods of defence. Higher values lead to shorter periods of defence because the higher the probability of intruding, the lower the expected value of expelling an intruder (i.e. the future probability of intruding also remains high). Thus, the higher values require longer periods of time to make up the cost of expelling the intruder in a given time period.

Because the future behaviour of nomadic intruders is unaffected by the aggressive behaviour of the residents, the rate at which these intruders enter the territory is constant throughout the first portion of the period of

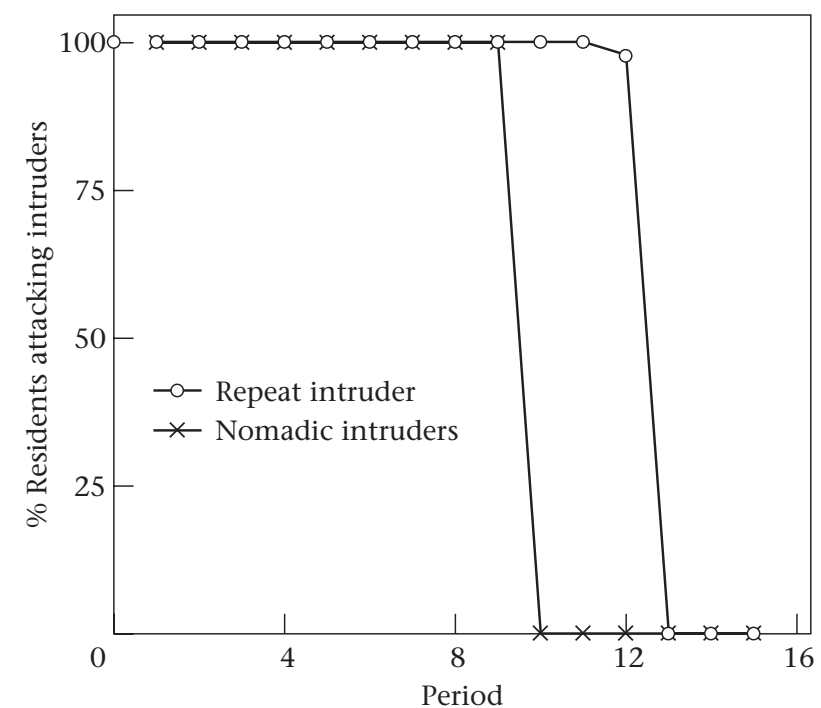

Figure 3. Percentage of residents attacking intruders for those territories that currently had an intruder. See Fig. 1 for the functional forms of intrusion probability for repeat and nomadic intruders and Table 1 for parameter values.

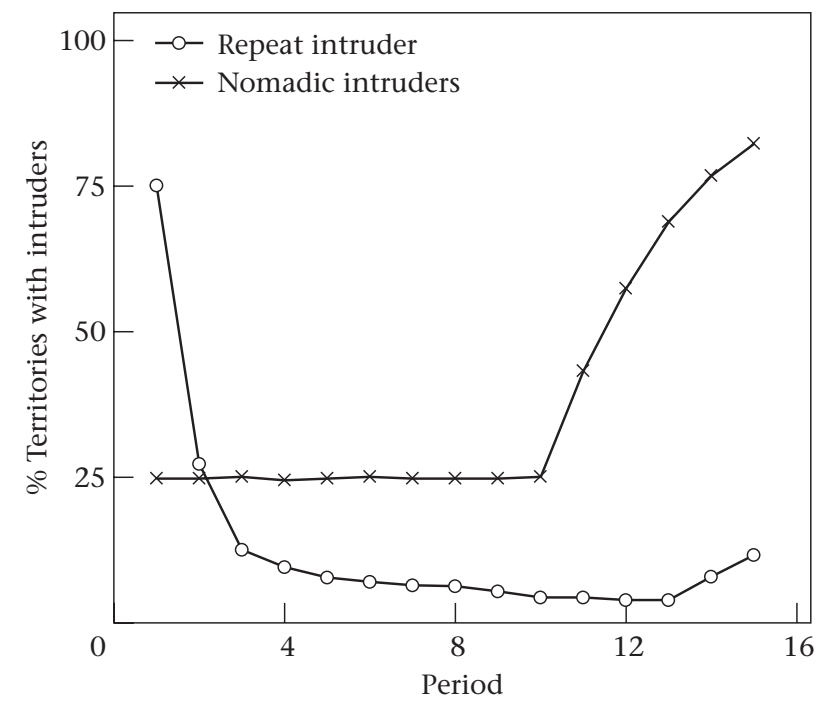

Figure 4. Percentage of territories $(N=10000)$ that currently had an intruder. See Fig. 1 for the functional forms of intrusion probability for repeat and nomadic intruders and Table 1 for parameter values.

tenure (Fig. 4). In contrast, the intrusion rates for repeat intruders declines precipitously as the period of tenure proceeds, as a consequence of the consistent attacks by the residents (Fig. 4).

\section{Temporal Changes in Aggressive Rates}

In field studies, it is difficult to keep track of the history of intrusions and attacks for individual intruders and territory owners, but it may be possible to estimate the proportion of territories on which residents are attacking intruders at any given time. When intruders are nomadic, 


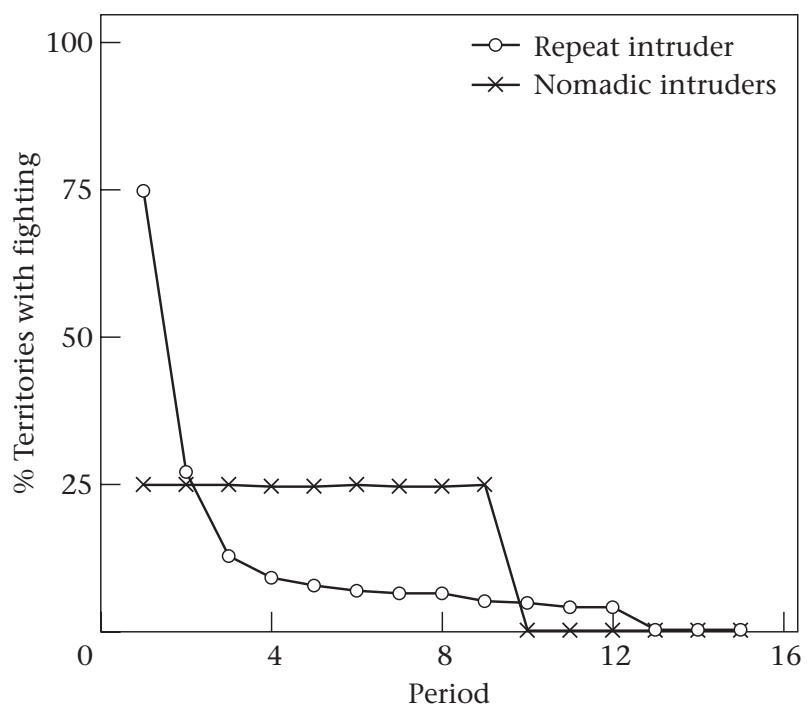

Figure 5. Percentage of territories $(N=10000)$ on which the resident attacks an intruder. See Fig. 1 for the functional forms of intrusion probability for repeat and nomadic intruders and Table 1 for parameter values.

the proportion of territories with fighting is expected to be constant during the first portion of the tenure period (Fig. 5) because the probability of intrusion is constant (Figs 1 and 4) and because each intrusion is met by attack by the resident (Fig. 3). With repeat intruders, there is a dramatic decline in the proportion of territories with fighting during the first portion of the tenure period because the probability of intrusion declines (Fig. 4); recall that residents continue to attack every intruder that enters (Fig. 3).

In both the nomadic and repeat intruder models, residents discontinue territory defence several time periods prior to the end of the tenure period (Fig. 3). Residents stop defending their territories because as they approach the time when they will leave their territory, the expected future benefits of defence decrease relative to the cost of defence. The exception to this rule occurs in situations where having an intruder at the end of the period of tenure eliminates most of the resident's fitness (e.g. $i_{\mathrm{e}}=0$ ). Not surprisingly, in these situations residents continue to attack intruders until the end of tenure period.

The response of intruders when residents stop defending their territories is qualitatively similar for nomadic and repeat intruder models: intruders begin to accumulate on the territories after the residents stop evicting them (Fig. 4). Quantitatively, however, the models differ. The fastest accumulation of intruders occurs in the nomadic intruder model, where intruders continue to enter territories at the same rate as before $\left(i_{\mathrm{o}}\right)$ regardless of whether they have been attacked. In situations with repeat intruders, many residents have 'trained' their intruder to stay out of their territory by the end of the tenure period, so the increase of intruders on territories occurs at a relatively low rate relative to the nomadic intruder model (Fig. 4).

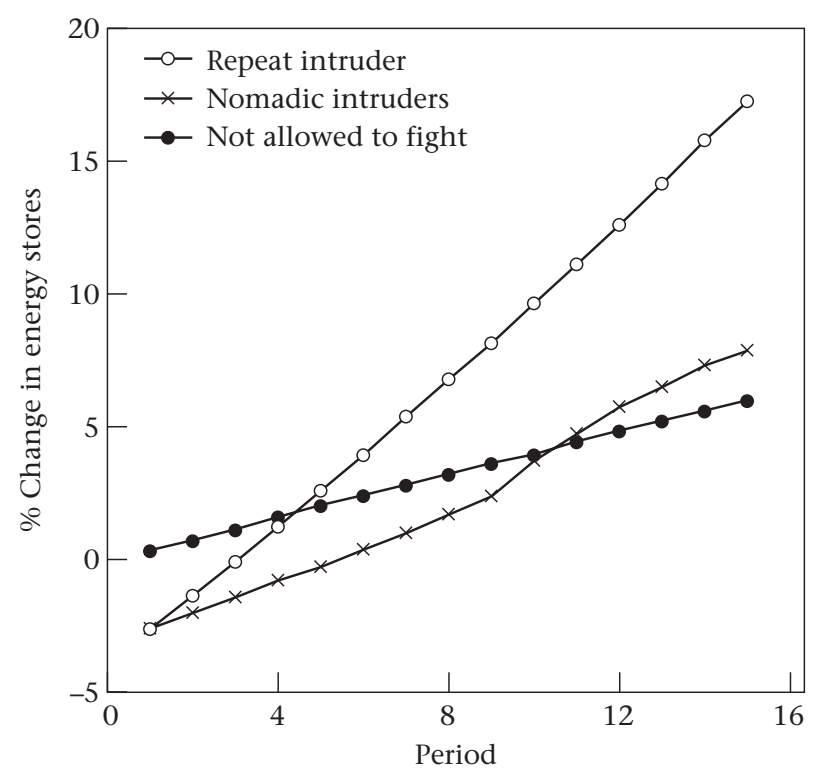

Figure 6. Average percentage change in the resident's starting energy reserves during the course of territory tenure. The lines compare the energy change for residents that are allowed to fight (i.e. follow the optimal decisions) for the two intruder types versus residents that are 'forced' to ignore intruders and instead always forage. See Fig. 1 for the functional forms of intrusion probability for repeat and nomadic intruders and Table 1 for parameter values.

\section{Energy Stores Over Time}

In both nomadic and repeat intruder models, residents invest energy in attacking intruders when these intruders first venture onto the territories and recoup the benefits of that investment later in the period of territory tenure (Fig. 6). Thus, residents go into an energy deficit when intruders begin to venture onto the territory, drawing on their energy stores to attack intruders instead of foraging. This strategy pays off in the long run, however, because repeat intruders who are punished when they initially venture onto the territory are less likely to return there in the future (Fig. 1), allowing the residents to devote most of their time to uninterrupted and unshared foraging during later time periods. Even residents with nomadic intruders experience a short-term decrease in intrusion probabilities as a result of attacks, because if the resident does not attack the intruder, the intruder remains on the territory (i.e. $P(n)=1.0$ ). If the resident attacks the intruder, however, then the probability that an intruder will arrive in the next period is the same as the population average (i.e. $P(n)=0.25$ in our nomadic intruder example).

The nature of the energy deficit experienced by a resident depends on the type of intruder. All else being equal, residents with repeat intruders experience a deficit that is smaller and of shorter duration than residents with nomadic intruders (Fig. 6) even when the initial probability of intruding is considerably lower ( 0.25 to 0.75$)$. These differences among intruder types can be explained by the average amount of intrusion that occurs over the resident's tenure, which is lower for repeat than for nomadic intruders. 


\section{DISCUSSION}

\section{Dynamic versus Static Models of Territory Defence}

Some of our results agree with those of earlier static models of territorial behaviour. For instance, our model indicates that there is a threshold of intrusion pressure, below which defence always occurs, and above which defence never occurs. This threshold also exists in static models that consider the effects of intruder pressure on the presence or absence of territory defence (reviews in Myers et al. 1981; Davies \& Houston 1984).

In other ways, however, the predictions of our dynamic models differ from those of previous static models. First, our results indicated that residents suffer an energy deficit at the beginning of their territorial tenure in order to accrue the benefits of decreasing future intrusions. Static approaches, given their 'snapshot' of costs and benefits, would not predict defence in these cases. For example, in the nomadic intruder model, defence costs at the beginning were so high that it took residents one-third of their tenure just to break even, and two-thirds of the tenure period before they surpassed the total energy gain of residents that never attacked intruders (Fig. 6). Thus, a long-term view of benefits changes predictions about when territories will be defended, and highlights the utility of considering net benefits throughout the period of territory tenure, rather than focusing on short-term gains and losses. The value of taking such a long-term view is illustrated by Davies \& Houston's (1983) classic study of winter territories in pied wagtails, Motacilla alba. On some days, territorial individuals would have had a higher foraging gain if they joined the flock; however, Davies \& Houston suggested that these individuals remained territorial because over the whole winter the net benefit to defending a territory was higher (Davies \& Houston 1983).

Second, the results of our models predict that residents will often reduce territorial defence near the end of the period of territory tenure. Cessation of defence is expected if residents voluntarily abandon territorial defence, if residents are able to predict when they will abandon their territories, and if the presence of intruders on the territory at the end of the tenure does not eliminate all accumulated fitness. These assumptions are probably valid for many animals that establish feeding territories, and they may also be true for other situations (e.g. breeding territories in which owners accumulate fitness on a daily basis; also see below). Again, static models looking at immediate costs and benefits do not predict such a pattern.

Although few workers have investigated the behaviour of animals just before they voluntarily abandon temporary feeding territories, there are some indications that residents may become less aggressive during this period. For example, rufous hummingbirds, Selasphorus rufus, establish feeding territories at stopovers during migration, and then voluntarily abandon these territories when they reach a condition that allows them to resume migration (Carpenter et al. 1983, 1993b). Carpenter et al. (1993a) were able to predict when individual hummingbirds would abandon their territories, based on relaxation of territorial defence by residents the day before they resumed migration. In Anolis aeneus lizards, juvenlies establish feeding territories in clearings; they then defend these territories until they grow to a certain size and emigrate to adjacent habitats (Stamps 1978, 1983). Small (e.g. newly settled) territory residents presented with same-size intruders are highly aggressive, but territory residents become much less aggressive to same-size intruders once they have reached the sizes at which they normally abandon their juvenile territories (Stamps \& Tollestrup 1984). Thus, although these juveniles are growing on their territories (and our model only incorporates changes in energy state), this example suggests that aggression may indeed decrease at the end of territory tenure.

\section{Repeat versus Nomadic Intruder Models}

Our results also indicate that residents should behave differently when confronted by a series of intruders, none of whom ever returns to the territory following attack (nomadic intruder model), versus when facing intruders who return to the territory even if attacked by the resident (repeat intruder model). For instance, at the beginning of the period of territory tenure, the threshold intrusion pressure $\left(i_{0}\right)$ required for the initiation of territory defence was much lower for the nomadic intruder model than for the repeat intruder model. In addition, in the nomadic intruder model, the proportion of territories that had intruders and the proportion that had fighting was constant over most of the tenure period, but both quickly declined in the repeat intruder model (Figs 4, 5). Interestingly, workers have observed especially high rates of aggression when birds first establish feeding territories (e.g. Copenhaver \& Ewald 1980; Gwinner et al. 1994; Turpie 1995); at least some of the intruders in these species were individuals who were residents in the same neighbourhood, suggesting that a repeat intruder model may apply to these species.

\section{Caveats and Future Directions}

For the sake of simplicity, the repeat intruder model considered situations in which only one intruder invaded a territory during the period of territory tenure. However, this model can be extended to situations in which several individuals intrude into the same territory, if we can assume that residents are capable of identifying intruders as individuals, and that aggressive behaviour directed by a resident at one intruder varies independently of aggressive behaviour directed by that resident to other intruders. In that situation, our results could be interpreted as predicting aggressive behaviour in residentintruder dyads, rather than predicting the behaviour of residents towards all intruders. There is abundant direct and indirect evidence that territorial vertebrates are capable of individual recognition (e.g. Catchpole \& Slater 1995; Gray \& Hurst 1997; Hojesjo et al. 1998; Owen \& Perrill 1998), so this assumption seems reasonable for this 
taxon, at least. The second assumption, that an individual's aggressive behaviour with one opponent can vary independently of its aggressive behaviour towards other opponents, has been amply validated in species that form dominant-subordinate relationships (review in Drews 1993), and is also likely to apply to many territorial species (Stamps 1999). Overall, having multiple, repeat intruders would not change the qualitative patterns of defence, but would increase the costs of defence and thus change the quantitative results and the quantitative differences between the nomadic and repeat intruder cases.

Our model was designed for feeding territories. For such territories, in which energy accumulation by the end of the period of tenure may provide an appropriate currency for fitness (e.g. Davies \& Houston 1983; Carpenter et al. 1993a), our modelling approach should be valid. However, results may not apply to aggression patterns on all-purpose or breeding territories. If a territory is used for a single breeding event (e.g. one clutch of eggs or litter of young), the time between the onset of defence and the realization of fitness benefits is likely to be longer than in the case for feeding territories, and thus the temporal patterns of aggression may differ from our results. On the other hand, some animals defend breeding territories in which mating occurs on a daily basis (e.g. territorial male dragonflies; Switzer 1997); if fitness accumulates throughout a resident's tenure, our modelling approach may apply in this situation.

Finally, because our model focused on the resident's point of view, we assumed a great deal about intruder behaviour. This simplification was extremely useful, for by controlling for variation in intruder behaviour, we were better able to interpret the resulting patterns of resident behaviour. Of course, intruder behaviour is often more complex than envisioned in our models. For instance, in heterogeneous habitats, intruders might not be able to estimate the resources available on a given territory without visiting the territory. In that case, the probability of intrusion should increase as a function of previous visits to the territory in which an intruder was rewarded by food, and not attacked by the resident (e.g. see Stamps \& Krishnan 1999). However, adding this assumption to our model would only accentuate the patterns observed in this study (e.g. residents should be even more likely to attack intruders on their first visits to the territory if rewarded intruders were more likely to return than were naïve intruders). Another possibility is that intruder behaviour might change as a result of intruder energy reserves over the course of the season. As long as these changes were consistent across intruders, this assumption could be incorporated into a modification of our current model, in which residents were able to predict changes in the probability of intrusion during the period of territory tenure. On the other hand, some assumptions about intruder behaviour would require new modelling approaches. For instance, if behaviour varied among intruders in the same area (e.g. in terms of persistence, nomadic versus repeat nature, etc.), and these differences were not signalled in ways that were obvious to residents (e.g. sex, age, colour patterns), then residents might not be able to discriminate one type from the other on their first visits to the territory. In that situation, other modelling techniques such as dynamic games would be required, because both residents and intruders would be learning about one another during an intruder's initial visits to the territory.

In conclusion, incorporating spatial learning into a dynamic model of territoriality generated patterns of resident aggression not predicted by earlier, static models. Some of these patterns have been supported by empirical data on feeding territories. Our study suggests that future models of territorial behaviour would do well to incorporate learning processes and consider the entire period of territory tenure. In addition, our results indicate that further modification of early models of territorial defence (e.g. investigating resident responses when confronted with several intruders with repeat visits) may yield new insights into patterns of defence in territorial animals.

\section{Acknowledgments}

We would like to thank J. Lucas, I. and J. Switzer, and two anonymous referees for comments on the manuscript. This work was partially supported by a Council for Faculty Research grant from Eastern Illinois University to P.V.S.

\section{References}

Anderson, J. R. 1995. Learning and Memory: an Integrated Approach. New York: J. Wiley.

Arcese, P. 1987. Age, intrusion pressure and defense against floaters by territorial male song sparrows. Animal Behaviour, 35, 773-784.

Archer, J. 1988. The Behavioural Biology of Aggression. Cambridge: Cambridge University Press.

Barta, Z. \& Giraldeau, L.-A. 2000. Daily patterns of optimal producer and scrounger use under predation hazard: a statedependent dynamic game analysis. American Naturalist, 155, 570-582.

Bednekoff, P. A. 1997. Mutualism among safe, selfish sentinels: a dynamic game. American Naturalist, 150, 373-392.

Blanchard, D. C. \& Blanchard, R. J. 1986. Punishment and aggression: a critical reexamination. In: Advances in the Study of Aggression (Ed. by R. J. Blanchard \& D. C. Blanchard), pp. 121-164. Orlando, Florida: Academic Press.

Carpenter, F. L. 1987. Food abundance and territoriality: to defend or not to defend? American Zoologist, 27, 387-400.

Carpenter, F. L., Paton, D. C. \& Hixon, M. A. 1983. Weight gain and adjustment of feeding territory size in migrant hummingbirds. Proceedings of the National Academy of Sciences, U.S.A., 80, 7259-7263.

Carpenter, F. L., Hixon, M. A., Beuchat, C. A., Russell, R. W. \& Patton, D. C. 1993a. Biphasic mass gain in migrant hummingbirds: body composition changes, torpor and ecological significance. Ecology, 74, 1173-1183.

Carpenter, F. L., Hixon, M. A., Russell, R. W., Paton, D. C. \& Temeles, E. J. 1993b. Interference asymmetries among age-sex classes of rufous hummingbirds during migratory stopovers. Behavioral Ecology and Sociobiology, 33, 297-304.

Catchpole, C. K. \& Slater, P. J. B. 1995. Bird Song. Cambridge: Cambridge University Press.

Clark, C.W. \& Mangel, M. 2000. Dynamic State Variable Models in Ecology. New York: Oxford University Press. 
Clutton-Brock, T. H. \& Parker, G. A. 1995. Punishment in anima societies. Nature, 373, 209-216.

Copenhaver, C. \& Ewald, P. W. 1980. Cost of territory establishment in hummingbirds. Oecologia, 46, 155-160.

Davies, N. B. 1978. Ecological questions about territorial behaviour. In: Behavioural Ecology: an Evolutionary Approach (Ed. by J. R. Krebs \& N. B. Davies), pp. 317-350. Oxford: Blackwell Scientific.

Davies, N. B. \& Houston, A. I. 1981. Owners and satellites: the economics of territory defense in the pied wagtail, Motacilla alba. Journal of Animal Ecology, 50, 157-180.

Davies, N. B. \& Houston, A. I. 1983. Time allocation between territories and flocks and owner-satellite conflict in foraging pied wagtails, Motacilla alba. Journal of Animal Ecology, 52, 621-634.

Davies, N. B. \& Houston, A. I. 1984. Territory economics. In: Behavioural Ecology: an Evolutionary Approach. 2nd edn (Ed. by J. R. Krebs \& N. B. Davies), pp. 148-169. Sunderland, Massachusetts: Sinauer.

Dill, L. M. 1978. An energy-based model of optimal feeding territory size. Theoretical Population Biology, 14, 396-429.

Drews, C. 1993. The concept and definition of dominance in animal behaviour. Behaviour, 125, 283-313.

Eason, P. 1992. Optimization of territory shape in heterogeneous habitats: a field study of the red-capped cardinal (Paroaria gularis). Journal of Animal Ecology, 61, 411-424.

Ebersole, J. P. 1980. Food density and territory size: an alternative model and a test on the reef fish Eupomacentrus leucostictus. American Naturalist, 115, 492-509.

Enquist, M. \& Leimar, O. 1983. Evolution of fighting behavior: decision rules and assessment of relative strength. Journal of Theoretical Biology, 102, 387-410.

Gordon, D. M. 1995. The development of an ant colony's foraging range. Animal Behaviour, 49, 649-659.

Gordon, D. M. \& Kulig, A. W. 1996. Founding, foraging and fighting: relationships between colony size and the spatial distribution of harvester ant nests. Ecology, 77, 2393-2409.

Grafen, A. 1987. The logic of asymmetric contests: respect for ownership and the desperado effect. Animal Behaviour, 35, 462-467.

Grant, J. W. A. 1993. Whether or not to defend? The influence of resource distribution. Marine Behaviour and Physiology, 22, 137-153.

Gray, S. J. \& Hurst, J. L. 1997. Behavioural mechanisms underlying the spatial dispersion of commensal Mus domesticus and grassland Mus spretus. Animal Behaviour, 53, 511-524.

Gwinner, E., Rodl, T. \& Schwabl, H. 1994. Pair territoriality of wintering stonechats: behaviour, function and hormones. Behavioral Ecology and Sociobiology, 34, 321-327.

Hilborn, R. \& Mangel, M. 1997. The Ecological Detective. Princeton, New Jersey: Princeton University Press.

Hinde, R. A. 1970. Animal Behavior: a Synthesis of Ethology and Comparative Psychology. 2nd edn. New York: McGraw-Hill.

Hixon, M. A. 1980. Food production and competitor density as the determinants of feeding territory size. American Naturalist, 115, 510-530.

Hojesjo, J., Johnsson, J. I., Petersson, E. \& Jarvi, T. 1998. The importance of being familiar: individual recognition and social behavior in sea trout (Salmo trutta). Behavioral Ecology, 9, 445-451.

Huntingford, F. A. \& Turner, A. 1987. Animal Conflict. London: Chapman \& Hall.

Kodric-Brown, A. \& Brown, J. H. 1978. Influence of economics, interspecific competion and sexual dimorphism on territoriality of migrant rufous hummingbirds. Ecology, 59, 285-296.

Maynard Smith, J. 1982. Evolution and the Theory of Games. Cambridge: Cambridge University Press.
Mesterton-Gibbons, M., Marden, J. H. \& Dugatkin, L. A. 1996. On wars of attrition without assessment. Journal of Theoretical Biology, $18,65-83$.

Myers, J. P., Connors, P. G. \& Pitelka, F. A. 1981. Optimal territory size and the sanderling: compromises in a variable environment. In: Foraging Behavior. Ecological, Ethological, and Psychological Approaches (Ed. by A. C. Kamil \& T. D. Sargent), pp. 135-158. New York: Garland Press.

Nuyts, E. 1994. Testing for the asymmetric war of attrition when only roles and fight durations are known. Journal of Theoretical Biology, 169, 1-13.

Owen, P. \& Perrill, S. A. 1998. Habituation in the green frog, Rana clamitans. Behavioral Ecology and Sociobiology, 44, 209-213.

Parker, G. A. 1974. Assessment strategy and the evolution of fighting behaviour. Journal of Theoretical Biology, 47, 223-243.

Patterson, I. J. 1980. Territorial behavior and limitation of population density. Ardea, 68, 53-62.

Poethke, H. J. \& Kaiser, H. 1987. The territoriality threshold: a model for mutual avoidance in dragonfly mating systems. Behavioral Ecology and Sociobiology, 20, 11-19.

Provencher, L. \& Vickery, W. 1988. Territoriality, vegetation complexity, and biological control: the case for spiders. American Naturalist, 132, 257-266.

Van Rhijn, J. G. \& Vodegel, R. 1980. Being honest about one's intentions: an evolutionary stable strategy for animal conflicts. Journal of Theoretical Biology, 85, 623-641.

Rohner, C. 1997. Non-territorial 'floaters' in great horned owls: space use during a cyclic peak of snowshoe hares. Animal Behaviour, 53, 901-912.

Schmidt-Nielson, K. 1984. Scaling. Why is Animal Size So Important? Cambridge: Cambridge University Press.

Schoener, T. W. 1983. Simple models of optimal territory size: a reconciliation. American Naturalist, 121, 608-629.

Shettleworth, S. J. 1998. Cognition, Evolution and Behavior. New York: Oxford University Press.

Smith, S. M. 1978. The 'underworld' in a territorial sparrow: adaptive strategy for floaters. American Naturalist, 112, 571-582.

Stamps, J. A. 1978. A field study of the ontogeny of social behavior in the lizard Anolis aeneus. Behaviour, 66, 1-31.

Stamps, J. A. 1983. The relationship between ontogenetic habitat shifts, competition and predator avoidance in a juvenile lizard (Anolis aeneus). Behavioral Ecology and Sociobiology, 12, 19-33.

Stamps, J. A. 1994. Territorial behavior: testing the assumptions. Advances in the Study of Behavior, 23, 173-232.

Stamps, J. A. 1999. Dominance and territoriality. In: Proceedings of the 22nd International Ornithological Congress, Durban (Ed. by N. J. Adams \& R. H. Slotow), pp. 1592-1605. Johannesburg: BirdLife.

Stamps, J. A. \& Eason, P. 1989. Relationships beween spacing behavior and growth rates: a field study of lizard feeding territories. Behavioral Ecology and Sociobiology, 25, 99-107.

Stamps, J. A. \& Krishnan, V. V. 1999. A learning-based model of territory establishment. Quarterly Review of Biology, 74, 291-318.

Stamps, J. A. \& Krishnan, V. V. 2001. How territorial animals compete for divisible space: a learning based model with unequal competitors. American Naturalist, 157, 154-169.

Stamps, J. A. \& Tollestrup, K. 1984. Prospective resource defense in a territorial species. American Naturalist, 123, 99-114.

Switzer, P. V. 1997. Factors influencing the site fidelity of a territorial animal, Perithemis tenera. Animal Behaviour, 43, 865-877.

Temeles, E. J. 1994. The role of neighbours in territorial systems: when are they 'dear enemies'? Animal Behaviour, 47, 339-350.

Tricas, T. C. 1989. Determinants of feeding territory size in the corallivorous butterflyfish, Chaetodon multicinctus. Animal Behaviour, 37, 830-841. 
Turpie, J. K. 1995. Non-breeding territoriality: causes and consequences of seasonal and individual variation in grey plover Pluvialis squatarola behaviour. Journal of Animal Ecology, 64, 429-438.
Waser, P. M. \& Wiley, R. H. 1979. Mechanisms and evolution of spacing in animals. In: Social Behavior and Communication (Ed. by P. Marler \& J. G. Vandenberg), pp. 159-223. New York: Plenum. 